\title{
The Use of Omega-3 Fatty Acids as an Alternative Treatment for Attention Deficit Hyperactivity Disorder in Children
}

\author{
Samra M. Suliman, MD \\ Department of Medicine, Division of Psychiatry, Faculty of Medicine \\ King Abdulaziz University, Jeddah, Saudi Arabia
}

\section{Correspondence}

Dr. Samra M. Suliman

P.O. Box 80216, Jeddah 21589, Saudi Arabia

e.M: samara_2018@hotmail.com

Submission: 15 Dec. 2015

Accepted: 17 Feb. 2015

\section{Citation}

Suliman SM. The use of omega-3 fatty acids as an alternative treatment for attention deficit hyperactivity disorder in children. JKAU Med Sci 2015; 22 (2): 47-52. DOI: 10.4197/Med. 22.2.7

\begin{abstract}
This case report studies the efficacy of omega-3 fatty acids as an alternative to using psychopharmacological agents for treating patients with Attention-Deficit Hyperactivity Disorder. While this study may not end the controversy concerning the effectiveness of omega-3, it does establish a very solid case for using omega-3 fatty acids as an augmenting agent along with a lower than recommended minimum starting stimulant dose.
\end{abstract}

\section{Keywords}

Attention-deficit hyperactivity disorder; Omega-3 fatty acids; Alternative treatment

\section{Introduction}

A ttention-Deficit Hyperactivity Disorder (ADHD), is the most commonly diagnosed neurodevelopmental disorder in childhood ${ }^{[1]}$, affecting 5-8 percent of school age children ${ }^{[1-7]}$ with symptoms persisting into adulthood in as many as 60 percent of cases (i.e., approximately $4 \%$ of adults). The significant increase in the diagnosis of ADHD saw a concomitant, and significant, increase in the prescription of stimulants - considered the gold standard and first line of treatment in the management of ADHD. However, stimulants carry the risk and the potential of abuse if misused. In addition to the side effects, this potential for substance abuse of stimulants led many caregivers and parents to resist starting their children on medication. For the past few years researchers have put in extensive effort to create an alternate treatment for ADHD.

Multiple research studies were conducted to explore the efficacy of diet modification, elimination of possibly offending products like added food colors or preservatives, behavioral interventions, etc. Nutritional supplements were also studied with Omega-3 ( $\omega-3)$ fatty acids being the primary focus of most studies. Several studies have demonstrated differences in $\omega-3$ fatty acids composition in plasma and in erythrocyte membranes in patients with ADHD compared to unaffected controls. Omega-3 fatty acids have antiinflammatory properties and can alter central nervous system cell membrane fluidity and phospholipid composition. Cell membrane fluidity in turn can alter serotonin and dopamine neurotransmission ${ }^{[8]}$. Clinical and biochemical evidence suggests that deficiencies of polyunsaturated fatty acids (PUFA) could be related to ADHD. Children and adolescents affected by ADHD have been shown to have significantly lower plasma and blood concentrations of PUFA and in particular, lower levels of $\omega-3$ fatty acids. These findings suggest that polyunsaturated fatty acids supplementation may reduce the attention and behavior problems associated with $\mathrm{ADHD}^{[9]}$.

Furthermore, a UK study that was conducted on children who did not carry the diagnosis of ADHD but had below average reading skills or dyslexia, found that lower docosahexaenoic acid (DHA) concentrations were associated with poorer reading ability, working 
memory performance and higher levels of parent-rated oppositional behavior and emotional liability ${ }^{[10]}$, which are findings and symptoms commonly associated with ADHD. Several trials of fish oil or long-chain $\omega$-3 fatty acids [mostly Eicosapentaenoic acid (EPA) and (DHA)] supplementation to children with ADHD have been conducted, yielding mixed results. To summarize the results of these multiple systematic reviews and meta analyses: no consensus has been reached regarding the influence of polyunsaturated fatty acids like $\omega-3$ on ADHD symptoms ${ }^{[1]}$.

This report presents a case of a child who was diagnosed with ADHD combined type and was started on $\omega-3$ fatty acids because of the parents' hesitation and discomfort with starting stimulants. This case does not end the controversy of using $\omega-3$ fatty acids but rather it sheds light on the use of $\omega-3$ fatty acids as a method of augmentation or as an alternative. Child psychiatrists and pediatricians should consider $\omega-3$ fatty acids as an option when patients or their families are not comfortable with the orthodox regimen of medication.

\section{Case Report}

This report concerns a case of a 7-year-old male, second grader, attending regular school with no prior history of formal psychiatric diagnosis. Patient was brought in by his parents following multiple school requests to have him evaluated by a psychiatrist because of his academic and behavioral difficulties in school.

Parents did admit that their child might have been more hyperactive compared to his siblings or to an average child his age but his hyperactivity was not a source of concern to the family.

They were able to ignore some behaviors and control others at home. Academic problems started to emerge and behavioral problems became more evident when he started going to school and more demands were placed upon him. The school reported that patient had difficulty maintaining his attention, was easily distracted, and frequently switched tasks without finishing any. Sometimes teachers felt that he was ignoring their commands and requests and that he had a difficult time following instructions, necessitating frequent reminders. Regarding his activity in class, he was reported to be extremely talkative, running around inappropriately, even climbing furniture; when forced to sit down, he was always fidgety / wiggly.
He was always trying to get out of his seat and leave the class for different reasons like going to the bathroom, throwing the trash or feeling thirsty. Patient's impulsive behavior was a continuous source of stress to the family due to concerns for his safety. The patient's behavior affected his social interactions with other classmates, who preferred not to play with him because of his inability to take turns, intrusiveness and frequent interruptions of others when they were talking.

The patient was never aggressive or physically belligerent but he frequently knocked over objects and banged into classmates, leading to fights with the other children in his class. The school described an incident that happened in a school field trip where he jumped into the pond to catch the ducks and hurt his knee. Parents reported similar symptoms at home and agreed that his behavior was becoming more dangerous and more difficult to control. Patient was screened for mood disorders like major depression, bipolar disorder, obsessive-compulsive disorder, anxiety disorder, and pervasive developmental disorders with no positive symptoms reported. Past history was insignificant to medical or psychiatric concerns or admission. Patient was a product of full-term, normal pregnancy (vaginal delivery with no complications).

He was exclusively breast-fed and met all developmental milestones as expected. Patient started going to daycare at the age of four. In kindergarten the school reported hyperactivity and difficulty playing with peers but because of the low teacher-to-student ratio ( 1 teacher per 3 students), the school had been able to manage his behavior. Family history was positive for similar symptoms. Father stated that growing up he was described as a hyperactive child; he also has a brother who dropped out of school due to behavioral problems. Socially, the patient had no friends in school despite his desire to make friends. He was part of the swimming team and did get along with his team members. Both school teachers and parents were provided with the Swanson, Nolan, and Pelham rating scale known as the SNAP form, which is a questionnaire that measures ADHD for children and adolescents ages 6-18 years. The SNAP-IV questionnaire, filled by both teachers and parents; strongly suggested ADHD combined type.

The case was discussed with the parents and they were informed that their child met the DSM-IV criteria for ADHD and the SNAP-IV results supported 
and confirmed the diagnosis. The patient level of functionality required an intervention and they were offered a treatment plan consisting of parent management training, organizational skills sessions, and an individualized class accommodation plan. The class accommodation plan included environmental, behavioral, homework and educational modifications. Examples of school accommodations were: Limiting distractions by assigning preferable seating near to the teacher, seating away from windows and doors, allowing frequent breaks, using visual aids and peer support.

The plan also included the use of psychopharmacology agents, mainly stimulants like amphetamine or methylphenidate. Parents were opposed to the use of psychopharmacological agents and wanted to know more about alternative approaches such as using supplementation. The family was specifically interested in using $\omega-3$ fatty acids.

The family was psych-educated and informed about the controversial results of using $\omega-3$ fatty acids on ADHD. After showing full understanding of ADHD treatment, the family decided to proceed with $\omega-3$ fatty acids trial before using psychopharmacological agents. The patient was started on $\omega-3$ fatty acids that is marketed under the name Kirkland fish oil. The Kirkland was used because it had the recommended ratio of EPA/DHA of 2:1. Initial dose was one tablet a day of $1200 \mathrm{mg}$ fish oil EPA (as ethyl esters) $410 \mathrm{mg}$ **, $\omega-3$ DHA (as ethyl esters) 274 mg. Before starting $\omega-3$ fatty acids, a baseline SNAP-IV form was filled by both teachers and parents - with plans to fill it on a weekly basis. The same schoolteachers filled the form for 12 weeks to minimize observation bias. Teachers were blinded from all the medication changes and adjustments. The SNAP-IV questionnaire was chosen to be the baseline and follow up questionnaire. The SNAP-IV Rating Scale questionnaire (18 items) covers two main areas of ADHD symptoms, namely inattention and hyperactivity.

It was selected because it is reliable and easily administrated. Research found SNAP-IV questionnaire to be valid in the population studied as long as the cut-off scores are modified to obtain the best sensitivity/specificity ratio based on the cultural and socioeconomic features of the population ${ }^{[12]}$. Patient baseline symptoms were above the cut-off for combined ADHD, which is 2.00 for teachers and 1.67 for parents. Patient showed mild improvement in the first two weeks he was started on $\omega-3$ fatty acids. The mild improvement was witnessed in class but not at home.

These changes were not sustained and around week 3 his SNAP-IV rating had reverted to be similar to his initial baseline SNAP-IV. On week 4 the dose was increased to two pills a day, total of $2400 \mathrm{mg}$ daily. Mild improvement was witnessed on week 8 . SNAP-IV form showed a mild decrease in severity of symptoms. Generally, the improvement was more on the behavioral side than the attention one. Patient was more flexible and was able to take turns with friends; he was following commands more frequently and was less disruptive in the class. Academically, he continued to struggle with finishing his work in class, paying attention to details and remembering where he placed his items. His exams scores did not reflect any changes and remained very low despite having extra time and needing fewer correct items for passing scores.

After being on $\omega-3$ fatty acids for 12 weeks, the family decided that they would like to add stimulants. Patient was started on Adderall (Dextroampetamine/ Amphetamine) $2.5 \mathrm{mg}$ for one week, followed by 5 mg once a day the following week. Except for mild loss of appetite, the patient showed no side effects to Adderall. Patient lost total of $2 \mathrm{lbs}$. Diet adjustment and adding high calorie meals were sufficient measures to stop the weight loss. The family was happy with the outcome and refused decreasing or discontinuing $\omega-3$ fatty acids.

\section{Discussion}

This report presents a case of a 7 year old child, diagnosed with combined type ADHD, who received $\omega$-3-fatty acid and was followed up for 12 weeks to observe if $\omega-3$ fatty acids would improve his ADHD symptoms and explore the possibility of having $\omega-3$ fatty acids as an alternative option to medication.

Attention-deficit hyperactivity disorder diagnosis was established by meeting the DSM-IV criteria of combined ADHD and the teacher/parent observation and filled questionnaire that were strongly suggestive of ADHD.

This case highlighted a common problem that child psychiatrists face in their daily practice in which they work with parents who have children affected academically and socially by their ADHD symptoms. In this case, the parents were in agreement that their child needed medical or behavioral intervention yet they 
were concerned over the long-term use of stimulants and other ADHD medications. Literature showed that initially parents have mixed or negative attitudes concerning the medication ${ }^{[13]}$. Other studies focusing on parents' view of medication, indicate that parents viewed non-medication treatment approaches, such as counseling and behavioral management, more favorably ${ }^{[14]}$.

The parents' initial refusal to use medications was led to the use of $\omega-3$ fatty acids. Parents were aware that supplements are not part of the current American Academy of Child and Adolescent Psychiatry Association Recommendation. Furthermore, the use of $\omega$-3-fatty acids continues to be highly controversial between researchers and physicians due to the lack of scientific evidence to support its efficacy.

The goal of this publication is to add data on the effect of $\omega-3$ fatty acids on ADHD patient to the body of literature with the hope of having more cases describing the effect of $\omega-3$ fatty acids and ending the long controversy over its efficacy on the treatment of ADHD. There are multiple systematic reviews, metaanalyses and case-control studies on the effect of $\omega-3$ fatty acids but the literature lacks individual case reports. Over the past few years multiple research studies conducted have consistently found a low level of DHA/EPA in erythrocyte membrane in patients diagnosed with ADHD and learning disability. This led to researchers exploring and testing the hypothesis of whether providing $\omega-3$ fatty acids will lead to any improvement of ADHD symptoms.

In this case the initial improvement witnessed in the patient was most likely related to the behavioral interventions and the school accommodations he received. The fading of the effect and reemergence of the symptoms was expected. Many studies and much research have confirmed the limited value of behavioral interventions on ADHD patients. MTA studies, which are one of the largest long-term studies, concluded that medication management was superior to behavioral treatment and to routine community care that included medication ${ }^{15]}$. FDA guidelines and recommendations for Adderall administration for children age 6-12 is to start with $10 \mathrm{mg}$ once daily and not exceed $30 \mathrm{mg}$. Patient was started on $2.5 \mathrm{mg}$ that was increased a week later to $5 \mathrm{mg}$.

Patient responded very well to $5 \mathrm{mg}$ of Adderall even though it is below the recommended startup dose. Improvement was reflected symptomatically as his level of attention, concentration and ability to control himself were observed both at home and at school. Teachers, who were blinded regarding all the medication changes, submitted a SNAP-IV with results reflecting significant improvement of $A D H D$ symptoms and improved exam scores. It was clear that $\omega-3$ fatty acids alone was ineffective in treating ADHD symptoms, but there is a strong possibility that taking $\omega-3$ fatty acids allowed for having a lower dose of stimulant. In this case it's difficult to confirm such a conclusion because the family refused discontinuing $\omega-3$ fatty acids, as they believed that it helped and did not want to take the risk of destabilizing their son.

\section{Conclusion}

This case report is a continuation of the current work on exploring alternative options for the treatment of ADHD. Psychopharmacological agents remain the first line of treatment for ADHD. Most if not all of the treatment alternatives are in various stages of scientific exploration and do not meet the standards to qualify as part of the evidence-based clinical practice recommendations ${ }^{[16]}$.

This would include alternative options like $\omega-3$ fatty acids. In the presented case, $\omega-3$ fatty acids did not improve ADHD symptoms but it shed light on the possibility of controlling ADHD symptoms by augmenting or having the combination of $\omega-3$ fatty acids along with a lower dose of stimulant. Omega-3 fatty acids supplementation is an acceptable and safe medical practice in the treatment and management of ADHD that should be considered for families who are interested in non-psych pharm alternatives.

\section{Conflict of Interest}

The author has no conflict of interest.

\section{Disclosure}

The author did not received any type of commercial support either in forms of compensation or financial for this study. The author have no financial interest in any of the products or devices, or drugs mentioned in this article.

\section{Ethical Approval}

Obtained.

\section{References}

[1] Visser SN, Danielson ML, Bitsko RH, Holbrook JR, Kogan MD, Ghandour RM, Perou R, Blumberg SJ. Trends in the parent- 
The Use of Omega-3 Fatty Acids as an Alternative Treatment for Attention Deficit Hyperactivity Disorder in Children S.M. Suliman

report of health care provider-diagnosed and medicated attention-deficit/hyperactivity disorder: United States, 2003-2011. J Am Acad Child Adolesc Psychiatry 2014; 53(1): 34-46.e2.

[2] Nunes EV, Rounsaville BJ. Comorbidity of substance use with depression and other mental disorders: from Diagnostic and Statistical Manual of Mental Disorders, fourth edition (DSM-IV) to DSM-V. Addiction 2006; 101 Suppl 1: 89-96.

[3] Barbaresi WJ, Katusic SK, Colligan RC, Pankratz VS, Weaver AL, Weber KJ, Mrazek DA, Jacobsen SJ. How common is attention-deficit/hyperactivity disorder? Incidence in a population-based birth cohort in Rochester, Minn. Arch Pediatr Adolesc Med 2002; 156(3): 217-224.

[4] Leibson CL, Katusic SK, Barbaresi WJ, Ransom J, O'Brien PC. Use and costs of medical care for children and adolescents with and without attention-deficit/hyperactivity disorder. JAMA 2001; 285(1): 60-66.

[5] Office of the Surgeon General (US), Center for Mental Health Services (US); National Institute of Mental Health (US). Mental Health: Culture, Race, and Ethnicity: A Supplement to Mental Health: A Report of the Surgeon General. Rockville (MD): Substance Abuse and Mental Health Services Administration (US); 2001. Publications and Reports of the Surgeon General. PMID: 20669516

[6] [No authors listed]. Clinical practice guideline: diagnosis and evaluation of the child with attention-deficit/ hyperactivity disorder. American Academy of Pediatrics. Pediatrics 2000; 105(5): 1158-1170.

[7] Centers for Disease Control and Prevention (CDC). Mental health in the United States. Prevalence of diagnosis and medication treatment for attention-deficit/hyperactivity disorder--United States, 2003. MMWR Morb Mortal Wkly Rep 2005; 54(34): 842-847.

[8] Bloch MH, Qawasmi A. Omega-3 fatty acid supplementation for the treatment of children with attention-deficit/ hyperactivity disorder symptomatology: systematic review and meta-analysis. J Am Acad Child Adolesc Psychiatry 2011; 50(10): 991-1000.

[9] Gillies D, Sinn JKh, Lad SS, Leach MJ, Ross MJ. Polyunsaturated fatty acids (PUFA) for attention deficit hyperactivity disorder (ADHD) in children and adolescents. Cochrane Database Syst Rev 2012; 7: CD007986.

[10] Montgomery P, Burton JR, Sewell RP, Spreckelsen TF, Richardson AJ. Low blood long chain omega-3 fatty acids in UK children are associated with poor cognitive performance and behavior: a cross-sectional analysis from the DOLAB study. PLOS ONE 2013; 8(6):

[11] Sonuga-Barke EJ, Brandeis D, Cortese S, Daley D, Ferrin M, Holtmann M, Stevenson J, Danckaerts M, van der Oord S, Döpfner M, Dittmann RW, Simonoff E, Zuddas A, Banaschewski T, Buitelaar J, Coghill D, Hollis C, Konofal E, Lecendreux M, Wong IC, Sergeant J; European ADHD Guidelines Group. Nonpharmacological interventions for ADHD: systematic review and meta-analyses of randomized controlled trials of dietary and psychological treatments. Am J Psychiatry 2013; 170(3): 275-289.

[12] Grañana N, Richaudeau A, Gorriti CR, O'Flaherty M, Scotti ME, Sixto L, Allegri R, Fejerman N. [Assessment of attention deficit hyperactivity: SNAP-IV scale adapted to Argentina]. Rev Panam Salud Publica 2011; 29(5): 344-349.

[13] Cohen NJ, Thompson L. Perceptions and attitudes of hyperactive children and their mothers regarding treatment with methylphenidate. Can J Psychiatry 1982; 27(1): 40-42.

[14] Bussing R, Zima BT, Gary FA, Garvan CW. Barriers to detection, help-seeking, and service use for children with ADHD symptoms. J Behav Health Serv Res 2003; 30(2): 176-189.

[15] [No authors listed]. A 14-month randomized clinical trial of treatment strategies for attention-deficit/hyperactivity disorder. The MTA Cooperative Group. Multimodal Treatment Study of Children with ADHD. Arch Gen Psychiatry 1999; 56(12): 1073-1086.

[16] Arnold LE. Alternative treatments for adults with attentiondeficit hyperactivity disorder. Ann NY Acad Sci 2001; 931 310-341. 


\section{استخدام الأحماض الدهنيه آوميجا كبايل دوائي في علاج اضطراب نقص الانتباه وفرط الحركه}

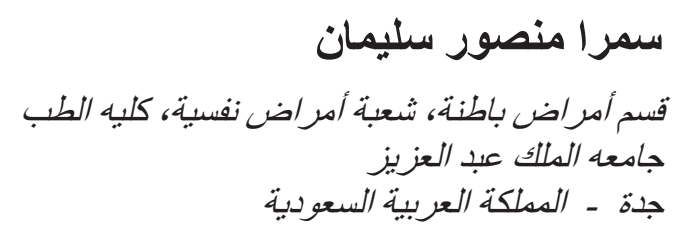

المستخطص. يعرض التقرير حالة طفل في الساعه من عمرة، بعاني من اضطر اب نقص الانتباة وفرط الحركة ودر اسة مدي فعالية استخدام الأحماض الدهنية أوميجا كبديل للعقاقير والأدوية الكميائية. علي الرغم من ان الحاله لم تقوم بإنهاء الجدل

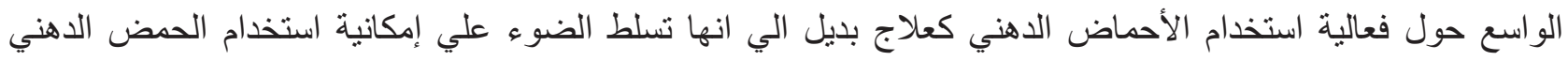
أو ميجا مع جر عات دو ائية اقل من الجر عات الدو ائية المتعارف علية، مما يخفف من حده الاثار الجانبية. 